\title{
A questão ambiental em cursos de administração de Mossoró (RN): documentos e percepções de coordenadores de curso analisados
}

\footnotetext{
Um dos instrumentos estratégicos e essenciais para o modelo de desenvolvimento sustentável é a Educação Ambiental (EA). Sendo assim, o objetivo geral deste trabalho é analisar a Educação Ambiental (EA) em bacharelados presenciais de Administração de quatro Instituições de Ensino Superior (IES) de Mossoró/RN. E objetivos específicos deste são: verificar o posicionamento dos coordenadores de curso sobre a EA nos seus respectivos cursos; e, verificar pressupostos de EA nos respectivos Projetos Pedagógicos dos Cursos (PPC's). O estudo foi direcionado para os cursos de graduação presencial em administração de quatro IES de Mossoró/RN, sendo uma Universidade Federal, uma Estadual, uma Privada e uma Faculdade. Foram entrevistados os coordenadores dos cursos e analisados os documentos. Apesar dos cursos pesquisados apresentarem a realização de práticas sustentáveis e o ensino da temática em algumas disciplinas, observou-se que as ações são pontuais e não desenvolvidas de forma transversal como preconiza a Lei 9.795/1999, o que poderia ser procedente do tipo de comprometimento dos atores envolvidos.
}

Palavras-chave: Instituições de Ensino Superior; Projeto Político-Pedagógico; Práticas Sustentáveis; Questões Ambientais.

\section{The environmental issue in Mossoró (RN) administration courses: documents and perceptions of course coordinators analyzed}

One of the essential and strategic tools for the sustainable development model is the Environmental Education (EE). Therefore, the general objective of this study is to analyze the environmental education (EE) in four presential bachelors of Business of Higher Education Institutions (HEI) of Mossoró/RN. And specific objectives of this are: Check the positioning of the course coordinators about the EA in their respective courses; and verify EA assumptions in their pedagogical projects of the courses (PPC's). The study was directed to the presential bachelors in Business of four HEls of Mossoró/RN, being a federal university, one state, one private and one college. They interviewed the coordinators of the courses and analyzed documents. Although the courses surveyed present the achievement of sustainable practices and the theme of teaching in some subjects, it was observed that the actions are isolated and undeveloped across the board as recommended by the Law 9.795 / 1999, which could be coming from the kind of commitment the actors involved.

Keywords: Higher Education Institutions; Political-Pedagogical Project; Sustainable Practices; Environmental Issues.

Topic: Gestão Ambiental e Biodiversidade

Reviewed anonymously in the process of blind peer.

Roberto Porfírio de Sousa Oliveira

Universidade Federal Rural do Semiárido, Brasil

http://lattes.cnpq.br/9554563412034173

rporfirio19@gmail.com

Ana Paula de Sousa Enéas

Universidade Federal Rural do Semiárido, Brasil

http://lattes.cnpq.br/9664383601032102

yanlapaula@hotmail.com

Livia Nascimento Rabelo

Universidade Federal Rural do Semiárido, Brasil

http://lattes.cnpq.br/6948244123047761

lih_nascimento14@hotmail.com
Received: 13/06/2016

Approved: 16/11/2016

Djanilton Alves de França

Universidade Federal Rural do Semi-Árido, Brasil

http://lattes.cnpq.br/0433277760569380

djanilton.f@gmail.com
Referencing this:

OLIVEIRA, R. P. S.; ENÉAS, A. P. S.; RABELO, L. N.; FRANÇA, D. A.. A questão ambiental em cursos de administração de Mossoró (RN): documentos e percepções de coordenadores de curso analisados. Revista Brasileira de Administração Científica, v.7, n.3, p.258-266, 2016. DOI: http://doi.org/10.6008/SPC2179-684X.2016.002.0018 


\section{INTRODUÇÃO}

Nas últimas décadas têm se intensificado o número de pesquisas e ações acadêmicas, legislações e medidas técnicas, administrativas e sociais para se rever o modelo de desenvolvimento (modelo de produção) em vigência na sociedade moderna. Principalmente devido ao acompanhamento da mídia, percebe-se que os danos, causados por esse modelo, ultrapassam gerações e, por vezes, são até irreversíveis. Sendo propostos como solução os modelos de desenvolvimento sustentável.

Um dos instrumentos estratégicos e essenciais para esse modelo sustentável é a Educação Ambiental (EA). Apesar de não haver um conceito universal, este tipo de educação visa promover a sensibilização dos alunos para as questões e problemas socioambientais. Por se tratar de uma questão cultural em que as pessoas são os objetos de mudança, os estudiosos, legisladores e as sociedades compreendem a educação como a ferramenta mais eficaz, graças a sua possibilidade de abordagem e reflexão na formação dos cidadãos e futuros profissionais.

Devido a tais fenômenos, o meio acadêmico (em especial, as próprias Instituições de Ensino Superior) está mais empenhado para a formação desses profissionais e cidadãos ambientalmente mais sensibilizados, já que seus educandos são a futura base técnica e formadora de opinião e atitudes. Para esse estudo, ainda se ressaltou aqueles, que por formação acadêmica, serão gestores das organizações. Isto é, buscou-se entender o processo da EA nos cursos de Administração, visto a importância do seu papel no modelo de produção atual.

Então, este trabalho busca respostas para as seguintes indagações: há uma Educação Ambiental sendo feita na formação dos administradores? Caso sim, coordenação está a par e dar suporte a essa EA? Os discentes desse curso se propõem a trabalhar as temáticas socioambientais? Ela está devidamente registrada no documento base do curso?

Sendo assim, o objetivo geral deste trabalho é analisar a Educação Ambiental (EA) em bacharelados presenciais de Administração de quatro Instituições de Ensino Superior (IES) de Mossoró/RN. E objetivos específicos deste são: verificar o posicionamento dos coordenadores de curso sobre a EA nos seus respectivos cursos; e, verificar pressupostos de EA nos respectivos Projetos Pedagógicos dos Cursos (PPC's).

Para que este estudo se faça consoante com os outros trabalhos da área e tenha um aporte teórico, foi feita uma pesquisa sobre o tema, que está apresentada brevemente a seguir, com destaques aos pontos mais relevantes sobre a EA (em especial, no Ensino Superior).

\section{REVISÃO TEÓRICA}

A consciência ambiental da sociedade foi fruto de um lento e contínuo desenvolvimento histórico. Durante longas décadas, e principalmente com o crescimento acelerado das sociedades, o ser humano passou a direcionar seus valores para um maior crescimento e aperfeiçoamento econômico, causando, consequentemente, uma barreira entre estes anseios e a preservação e atenção ao meio ambiente (ALMEIDA, 2002; ELKINGTON, 2001). 
Com o advento da sociedade contemporânea e os diversos avanços tecnológicos, o ser humano passou a ir percebendo os impactos ambientais causados durante todos esses anos. Com isso, surgem as primeiras discussões acerca de uma forma de progresso econômico, que minimizem os impactos causados, de forma a não prejudicar as gerações futuras. Assim, o desenvolvimento sustentável, revelou-se uma nova maneira de perceber as soluções para os problemas globais, que não se reduzem apenas à degradação ambiental, mas incorporam também dimensões sociais, políticas e culturais. Muitos eventos aconteceram para que essa consciência fosse tomada (CAMARGO, 2005). Sendo assim, um breve resumo foi feito desses encontros, que discutiram a mudança dos padrões a partir da conscientização, por Andrade (2008):

Conferência de Estocolmo, 1972 - a educação ambiental foi reconhecida como elemento crítico no combate à crise ambiental;

Encontro Internacional sobre Educação Ambiental, realizado em Belgrado, 1975 formulam-se princípios e orientações para um programa mundial de Educação Ambiental, que deveria ser contínua, multidisciplinar e integrada às diferenças regionais;

Primeira Conferência Intergovernamental sobre Educação Ambiental aos Países Membros, realizada em Tbilisi, 1977 - entende-se que a Educação Ambiental deve promover a solução dos problemas ambientais e ter como objetivo a melhoria da qualidade de vida por meio de um enfoque interdisciplinar e de participação ativa dos indivíduos e da coletividade. No que diz respeito às universidades, acentuou-se a necessidade da EA para estudantes de todos os campos. Desta forma, a temática ambiental deixa de ser restrita às ciências técnicas e naturais, passando a ser também contemplada nas ciências sociais e artísticas, o que representou o reconhecimento das relações entre natureza, tecnologia e sociedade. A conferência considerou a universidade como centro de pesquisa e formação de pessoal qualificado, definindo que a educação ambiental nas escolas superiores deve ser diferente da educação tradicional, para isso, recomendou o desenvolvimento da pesquisa e a aplicação do enfoque interdisciplinar (em qualquer disciplina) nas correlações homem e a natureza;

Congresso Internacional sobre Educação e Formação Ambientais, realizado em Moscou (1987) - estabeleceu estratégias da EA para a década de 1990. Quanto a Educação universitária propõe o desenvolvimento de sensibilização das autoridades acadêmicas sobre a temática ambiental, o desenvolvimento de programas de estudo na área, o treinamento de professores, e a cooperação institucional;

Conferência do Rio (Rio-92) reconhece a necessidade de se erradicar o analfabetismo ambiental e estimular a capacitação de recursos humanos para a área ambiental. Reforça a necessidade do enfoque interdisciplinar, prioriza a educação para o desenvolvimento sustentável e a conscientização popular, promove o treinamento.

Nesse contexto, a educação desempenha um papel central capaz de formar cidadãos críticos que assumam uma posição transformadora, a fim de beneficiar a conscientização no processo de reversão da degradação ambiental, visando promover a transformação dessa realidade levando em consideração aspectos ecológicos, políticos, econômicos, culturais e sociais. Portanto, a educação ambiental auxilia no debate sobre a incorporação da temática ambiental e se coloca como um dos elementos fundamentais contra a crise ambiental atual (MELGAR, 2005).

Nota-se que a Educação Ambiental, apesar de não ter um conceito único, é uma educação crítica da realidade, cujo objetivo central é a compreensão e a reflexão da relação entre humanidade e natureza, analisando-a em seus diversos aspectos (do biológico ao cultural). Ou seja, buscando o equilíbrio local e global para melhoria na qualidade da vida, a EA transforma valores e atitudes e cria uma ética baseada na 
relação sociedades-natureza (MELGAR, 2005). A Política Nacional de Educação Ambiental, regida pela Lei № 9.795 de 27 de abril de 1999, define o termo Educação Ambiental como:

Processos por meio dos quais, o indivíduo e a coletividade constroem valores sociais, conhecimentos, habilidades, atitudes e competências voltadas para a conservação do meio ambiente, bem de uso comum do povo essencial à sadia qualidade de vida e sua sustentabilidade (BRASIL, 1999).

No intuito de reforçar as práticas de EA discutidas em diversas conferências de caráter internacional, o Brasil sanciona a Lei no 9.795 de 27 de abril de 1999, que institui a Política Nacional de Educação Ambiental (PNEA) (SILVA, 2015). Nela é dito que todo o Ensino deve trabalhar a EA, seja na modalidade não-formal (comunitária, por exemplo), quanto na formal (nas instituições de ensino regular). Também é dito que a EA não deve ser implantada como disciplina específica, mas como prática contínua nos cursos, sendo facultadas na pós-graduação, extensões e nas áreas técnicas da área e de educação (BRASIL, 1999).

Sendo assim, a educação ambiente deve estar presente em todos os lugares educativos. Sendo assim, o projeto pedagógico de qualquer escola ou universidade deve conter este tema. Esta, mesmo após ser bastante debatida não se tornou uma disciplina da grade escolar, pois sua abrangência deve ir além. 0 tema educação ambiental segundo o Conselho Federal de Educação deve permear todas as disciplinas, pois seu enfoque é interdisciplinar, pois cada disciplina tem a sua contribuição das atividades de educação ambiental, uma espécie de "revolução pedagógica". Além disso, a educação ambiental também deve ter participação de toda comunidade, sendo necessário sair das "quatro paredes" da sala de aula.

\section{METODOLOGIA}

Este trabalho configura-se de natureza qualitativa que fez uso de procedimentos qualitativos de coleta de dados para fins descritivos. O estudo foi direcionado para os cursos de graduação presencial em administração de quatro Instituições de Ensino Superior (IES) de Mossoró-RN, sendo uma Universidade Federal, uma Estadual, uma Privada e uma Faculdade.

Esse estudo contou com os seguintes procedimentos metodológicos: análise de documentos e entrevistas. Segundo Lakatos e Marconi (2010) "entrevista é um encontro entre duas pessoas, a fim de que uma delas obtenha informações a respeito de determinado assunto, mediante uma conversação de natureza profissional". Foram realizadas entrevistas com roteiros semiestruturados com quatro coordenadores dos cursos de administração das IES de Mossoró-RN. Para esta pesquisa os coordenadores serão denominados de: Coordenador A para o coordenador da Universidade Federal, Coordenador B para o da Faculdade, Coordenador C para o da Universidade Estadual e Coordenador D para o da Universidade Privada. O critério de escolha para esta classificação é a ordem com que as entrevistas foram realizadas, sendo estas gravadas e transcritas mediante autorização dos entrevistados e após assinarem um Termo de Consentimento Livre e Esclarecido.

Para a análise documental foram pesquisados os projetos pedagógicos dos cursos dessas Instituições, com o intuito de identificar referências às questões ambientais em tais documentos, bem como confirmar os dados levantados nas entrevistas. Para Martins et al. (2009), a pesquisa documental é "característica dos 
estudos que utilizam documentos como fonte de dados, informações e evidências". Vale ressaltar que a Universidade Federal apresenta dois PPCs vigentes, um de 2009 e outro de 2014. Os demais apresentaram um único PPC para seus respectivos cursos. Para a análise dos dados foi utilizado o método de análise de conteúdo. De acordo com Martins et al. (2009), "é uma técnica de se estudar e analisar a comunicação de maneira objetiva e direta".

\section{RESULTADOS E DISCUSSÃO}

Devido ao número de dados coletados nas entrevistas, para este estudo, em particular, foram discutidas algumas das questões pertinentes ao objetivo, que é o de analisar a EA em bacharelados presenciais de Administração de quatro IES de Mossoró/RN.

Inicialmente, os coordenadores foram abordados com o questionamento se a temática ambiental vem sendo desenvolvida de alguma forma nos cursos de Administração que coordenam, caso as respostas fossem afirmativas de que modo estão sendo desenvolvidas. Os quatro entrevistados responderam que sim, e de forma sintetizada, complementaram que essas questões são trabalhadas nos cursos através da oferta de disciplinas obrigatórias (para algumas instituições), optativas e atividades complementares como eventos científicos e projetos de pesquisa e extensão. A seguir são apresentados relatados dos entrevistados que evidenciam o modo como às questões ambientais são desenvolvidas nos cursos pesquisados:

Sim. Tem uma disciplina obrigatória no PPC de 2009, e vai continuar, permanecer e já está no PPC de 2014, que é a disciplina gestão ambiental e responsabilidade social, pronto essa disciplina ai. Mais também tem algumas disciplinas que trabalham essa temática, por exemplo, em marketing tem um capítulo, uma aula que a gente dedica para a relação do marketing com a parte ambiental. Dentre outros cursos, pois a professora Elizabete trabalha a questão social, o pessoal de sociologia também toca em alguns aspectos, e o professores as vezes mesmo que não tenha na disciplina na ementa ele pode inserir no programa, como as vezes tem não programa, e na ementa e ele pode também ultrapassar, não tocar nessa temática (COORDENADOR A).

Então, com relação ao curso, eu vejo que a gente poderia ter mais algumas disciplinas focadas na área ambiental, aqui a gente dispõe de uma disciplina optativa na verdade, que é de gestão ambiental. [...] Outro local que a gente utiliza é na disciplina de tópicos especiais, a gente também sempre insere uma ou duas unidades que tratam de gestão da qualidade e da área ambiental também, então a gente reforça com o professor que vai passar a disciplina que ele busque esse viés porque normalmente essa disciplina ela é trabalhada no sétimo e no oitavo período, então é no final do curso, tanto tópicos como gestão ambiental (COORDENADOR B).

Sim, nós começamos a enxergar as questões ambientais principalmente na ligação com passivos ambientais, que as possíveis decisões possam vir a causar, além de questões de ordem de clima organizacional, impacto de atos administrativos então isso aí a gente trabalha muito também voltado para a consequência, o que é que isso pode causar. E no tocante a ambiental mesmo, as optativas do curso, a partir do sexto período nós temos cinco optativas, a gente coloca sempre disciplinas voltadas a questões ambientais (COORDENADOR C).

É uma disciplina obrigatória. Meio Ambiente e Sustentabilidade é o nome da disciplina. Na grade atual, eles veem essa disciplina na segunda série. Ela consta no PPC. É até uma orientação do MEC que a gente trabalhe essa disciplina Meio Ambiente e Sustentabilidade e que dentro dessa disciplina eles trabalhem as questões das normas, a questão do meio ambiente, a questão da sustentabilidade e desenvolvem uns trabalhos práticos dentro das cidades e arredores (COORDENADOR D). 
Por esta razão, Campos et al. (2007) afirmam que, apesar de uma prática recente nos cursos de Administração, as questões ambientais vêm sendo desenvolvidas através de disciplinas relacionadas à gestão ambiental e correlatas a esta, tendo em vista que o futuro Administrador precisa ter uma bagagem teórica que lhe proporcione atender às exigências do mercado.

Ao questionar os coordenadores sobre a importância de contemplar a questão ambiental no Projeto Pedagógico do Curso, as respostas foram diretas e muito próximas umas das outras, afirmando ser este o papel da interdisciplinaridade no curso da administração, visto que o futuro profissional poderá atuar em muitas áreas, não sendo possível definir um único mercado de trabalho. Este fato pode ser corroborado com a fala do Coordenador C:

Interdisciplinaridade. A gente não tem como definir onde o nosso aluno vai trabalhar. Se ele sair e ele for trabalhar numa empresa de agronegócio tem questão ambiental. Se ele sair daqui e for trabalhar num hospital, tem questão ambiental. Se ele sair e for trabalhar numa indústria, tem questão ambiental, né? [...] Então se a gente não falar aqui dentro eles não vão conseguir alcançar a profundidade do que eles necessitam saber. Então aqui na verdade se a gente disser que aqui a gente vai sanar todas as dúvidas, os anseios, não vamos, até porque a gente não tem esse conhecimento tão aprofundado, mas aqui é o "start" é aqui onde ele vai ver que existe.

A importância de contemplar a questão ambiental no principal documento que rege o curso, o PPC, é abordada por Batista et al. (2011), quando mencionam a relevância de incorporar a dimensão ambiental no âmbito da formação. Desse modo, os autores ressaltam que promover essa discussão nos espaços acadêmicos é um dos principais desafios a serem enfrentados pelos educadores e pelas instituições de ensino. A partir de uma perspectiva humanizadora do processo educativo, entende-se que a presença do enfoque ambiental se faz necessária, constituindo-se em um desafio das instituições de ensino, compreendendo que a tarefa da educação é formar para uma atitude responsável e a partir de uma consciência e responsabilidade social. Quando indagados se as questões ambientais estavam bem contempladas no curso que coordenam, houve uma divergência entre as respostas dadas pelos entrevistados.

Acredito que sim. Porque, porque não é possível nós temos dois professores que trabalham isso, não só no ensino mais na pesquisa e na extensão. Tá certo, então assim, eu acho que o curso tem que ter várias vertentes, embora essa vertente contemple as demais, a gente tem as duas professoras por terem doutorado e serem bem ativas no curso, elas conseguem sim contemplar de forma satisfatória (COORDENADOR A).

Não. Eu acho que poderiam estar mais bem contempladas, por exemplo, se a gente ofertasse uma disciplina como obrigatória (COORDENADOR B).

Assim... Ainda é algo muito nebuloso, até onde vai à atuação do administrador nisso, mas eu considero que hoje estão bem contempladas, principalmente porque a nossa matriz curricular não tem só nossas disciplinas, a gente também tem disciplinas de gestão ambiental [o curso], a gente chama os professores de lá e eles também ministram disciplinas aqui (COORDENADOR C).

Sim. Como a gente tem essa disciplina específica, então não tem como fugir. Mas, além disso, dentro de outras disciplinas como Antropologia e Cultura, como o próprio Empreendedorismo (se trabalha muito Empreendedorismo Sustentável e Empreendedorismo Ambiental), a gente vê o trabalho prático dos alunos, muitas vezes eles já levando o foco do empreendedorismo para esse lado ambiental. Muitos projetos que eles desenvolvem, por exemplo, com material reciclável, muitas ações que eles fazem são em ONGs e é aí que eles tratam essa questão ambiental (COORDENADOR D). 
Como pode ser observado nos discursos apresentados anteriormente, três coordenadores afirmaram que as questões ambientais estão bem contempladas nos cursos de Administração em que estão envolvidos, em virtude da grade curricular apresentar disciplinas específicas na área, além da temática estar associada à pesquisa e extensão. No entanto, apenas um dos coordenadores afirmou que a ausência de uma disciplina obrigatória na estrutura curricular do curso que coordena inviabiliza uma maior discussão das questões ambientais em sala de aula.

Segundo Barbieri (2004), incorporar a temática ambiental nas disciplinas dos cursos de administração é uma das principais dificuldades encontradas na formação do futuro administrador, uma vez que, conseguir romper com o dilema empresa versus meio ambiente, e mudar o comportamento dos empresários que aliam as questões ambientais a custos ao invés de oportunidades de melhoria na qualidade da empresa, é um processo desafiador.

Foi questionado aos coordenadores se existe consideração dos aspectos legais de Educação Ambiental no PPC. Em paralelo as respostas dadas pelos entrevistados a questão referente aos aspectos legais da EA foram também analisadas junto aos PPCs dos cursos pesquisados, com intuito de corroborá-las. O Coordenador A afirmou que os dois PPCs vigentes mencionavam a lei 9795/1999, que institui a Política Nacional de Educação Ambiental, fato este que pôde ser observado a partir da leitura dos dois documentos. Os Coordenadores B e C afirmaram que não há menção de aspectos legais de EA no PPC dos cursos que coordenam, sendo esta afirmação confirmada na análise do documento. O Coordenador $D$ afirmou que o PPC da sua instituição menciona os aspectos legais da EA, conforme registrado no documento.

O PPC 2014 da Faculdade Particular não se refere nem a Lei 9795/99 nem as políticas oficiais da EA, porém nota-se na ementa das disciplinas e no PPC como um todo a preocupação com a temática. Inclusive, o objetivo do curso destaca a responsabilidade ambiental dos formandos nessa IES:

Formar profissionais com sólida formação geral e profissional, habilitados a atuarem no mercado com proposta ética, responsabilidade social e ambiental, na compreensão do seu meio, identificando as possibilidades de umas práxis positiva na ampliação da cidadania para uma parcela maior da sociedade (PPC DA FACULDADE PARTICULAR, 2014, p. 12).

Guerra e Figueiredo (2014) dizem que uma das três dimensões necessárias para a ambientalização da universidade é a que abrange o currículo. Esta é a comporta "disciplinas e projetos político- pedagógicos, concebidos na perspectiva do pensamento complexo, da inter e da transdisciplinaridade" (GUERRA et al., 2014).

Em seguida, os entrevistados foram questionados quanto a realização de práticas sustentáveis, se ocorre estímulo por parte da instituição, coordenação e professores, caso as respostas fossem afirmativas, de que forma estas são realizadas. A seguir, os coordenadores apresentam alguns exemplos dessas práticas:

Então, vamos lá. A instituição sim, né?! A Universidade tem práticas que trabalhem isso. $O$ curso, sim. A coordenação, não, diretamente não. A gente apenas não atrapalha quem está fazendo, então assim, não foi uma proposta dessa coordenação fazer um projeto com base da coordenação para o curso, e sim professores trabalhando nessas frentes, na verdade essa vertente (COORDENADOR A).

Fazemos a troca de lâmpadas, a gente teve um processo de trocas dessas lâmpadas, eram lâmpadas que gastavam mais energias e foi levado pros alunos, conversados com eles (COORDENADOR B). 
Sim, a gente procura não só em sala de aula, por exemplo: Agora a gente fez o projeto de urbanização aqui do bloco. [...] Aí vai utilizar construção de bancos com materiais reutilizados das obras da Universidade, então a gente vai tentar fazer tudo isso com reuso e o uso consciente (COORDENADOR C).

A gente tem esses projetos específicos, que são feitos nas séries e que eles sempre envolvem. Continuado, dentro do curso, existe um projeto de coleta de pilhas, baterias e esses materiais. [...] Aqui no campus, aqui na instituição. A gente faz a coleta, depois encaminha para uma empresa e ela faz o descarte (COORDENADOR D).

A necessidade de internalização de práticas ambientais no escopo das Instituições de Ensino Superior demanda um esforço de fortalecer visões integradoras, que se centradas no desenvolvimento de ações, rompem as barreiras da teoria e assumem a prática, a fim de estimular uma reflexão em torno da construção de sentidos que estabelecem relações entre os indivíduos e o meio ambiente (TRISTÃO, 2004).

Por fim, os coordenadores entrevistados foram indagados sobre o que eles acham que a instituição a qual estão vinculados poderiam fazer para contribuir na formação de cidadãos mais responsáveis ambientalmente. O Coordenador A respondeu que a instituição poderia divulgar, de uma maneira mais ampla, os projetos desenvolvidos pelos seus cursos. O coordenador B acredita que a instituição poderia implantar mais práticas ambientais em seus espaços, de modo que os alunos percebam o meio ambiente ao redor deles. O Coordenador $\mathrm{C}$ afirma que a Universidade já desempenha esse papel, porém assume que a responsabilidade não é apenas dos gestores, mas também dos discentes. $E$ o Coordenador $D$ afirma que as ações já vêm sendo desenvolvidas, e não somente nos cursos de Administração, mas em outros cursos da Universidade.

Ruscheinsky et al. (2012) afirmam que, "a educação ambiental pretende lidar com todos os aspectos da vida do cidadão, como um sujeito em construção, no vir-a-ser em seu tempo e das exigências de seu espaço". Nesse sentido, observa-se o relevante papel das IES em assumir a responsabilidade como espaços de debates da temática e oportunizar a formação de cidadãos mais responsáveis ambientalmente.

Para isso, é necessário que ocorra um processo de ambientalização nas IES como um todo, envolvendo seus professores, gestores, alunos, funcionários, departamentos, cursos, projetos de pesquisa e de extensão e o entorno da instituição, com o objetivo de integrar todas as partes envolvidas no processo de inserção da questão ambiental.

\section{CONCLUSÕES}

Diante do exposto, conclui-se que compreender e fomentar a EA no Ensino Superior é um dos passos relevantes da Academia para mudar o pensamento e o comportamento das sociedades, ainda mais daqueles que se instruem para gerir as organizações.

Esse estudo viabilizou um diagnóstico em quatro cursos de Administração de Instituições de Ensino Superior em Mossoró/RN, com o intuito de analisar pressupostos de Educação Ambiental nesses cursos, sob os discursos dos coordenadores e do principal documento que rege o curso, o PPC. Apesar dos cursos pesquisados apresentarem a realização de práticas sustentáveis e o ensino da temática em algumas 
disciplinas, observou-se que as ações são pontuais e não desenvolvidas de forma transversal como preconiza a Lei 9.795/1999, o que poderia ser procedente do tipo de comprometimento dos atores envolvidos.

Portanto, observa- se a necessidade de reflexão em adotar práticas pedagógicas na superação das dificuldades relacionadas à fragmentação disciplinar do ensino da temática ambiental nos cursos de administração pesquisados. Em suma, espera-se que os resultados aqui apresentados tenham contribuído para evidenciar a responsabilidade das IES e, em particular os cursos de administração em despertar interesse e realizar pesquisas mais aprofundadas sobre os temas propostos.

\section{REFERÊNCIAS}

ALMEIDA, F.. O bom Negócio da Sustentabilidade. Rio de Janeiro: Nova Fronteira, 2002.

ANDRADE, A. C.. Educação ambiental no ensino superior: Disciplinaridade em discussão. Dissertação (Mestrado em Educação) - Universidade Estácio de Sá, Rio de Janeiro, 2008.

BARBIERI, J. C.. A educação ambiental e a gestão ambiental em cursos de graduação em administração: objetivos, desafios e propostas. Revista Brasileira de Administração Pública, Rio de Janeiro, v.38, n.6, p.919-946, 2004.

BATISTA, M. S. S.; RAMOS, M. C. P.. Desafios da Educação Ambiental no Ensino Superior: das Políticas às Práticas no Brasil e em Portugal. In: SIMPÓSIO BRASILEIRO DE POLÍTICA E ADMINISTRAÇÃO DA EDUCAÇÃO, 25. Anais. São Paulo: ANPAE, 2011.

BRASIL. Lei № 9795, de 27 de abril de 1999. Dispõe sobre a educação ambiental, institui a Política Nacional de Educação Ambiental e dá outras providências. Brasília: DOU, 1999.

CAMARGO, A. L. B.. Desenvolvimento Sustentável:

Dimensões e desafios. 2 ed. Campinas: Papirus, 2003.

CAMPOS, L. M. S.; SHIGUNOV NETO, A.. A Gestão Ambiental nos Cursos de Administração: discussões preliminares sobre sua importância. RACE: Revista de Administração Cesusc, Florianópolis, n.2, p.9-24, 2007.

ELKINGTON, J.. Enter the Triple Bottom Line. In: Henriques, A.; Richardson, J.. The Triple Bottom Line: Does it All Add
Up? Assessing the Sustainability of Business and CSR. London: Earthscan Publications, 2004. p.1-16

GUERRA, A. F. S.; FIGUEIREDO, M. L.. Caminhos e desafios para a ambientalização curricular nas universidades: panorama, reflexões e caminhos da tessitura do programa Univali Sustentável. In: RUSCHEINSKY, A. et al..

Ambientalização nas Instituições de Educação Superior no Brasil: caminhos trilhados, desafios e possibilidades. São Carlos: EESC/USP, 2014. p.145-164.

LAKATOS, E. M.; MARCONI, M. A.. Técnicas de pesquisa: planejamento e execução de pesquisas, amostragens e técnicas de pesquisa, elaboração, análise e interpretação de dados. 7 ed. São Paulo: Atlas, 2010.

MELGAR, M. J. A.. EDUCAÇÃO AMBIENTAL NAS EMPRESAS: um estudo de caso na Fischer Fraiburgo Agrícola Ltda. Dissertação (Mestrado em Administração) - Universidade Federal de Santa Catarina, Florianópolis, 2005.

SILVA, A. N.. Ambientalização curricular na Educação Superior: um estudo na Pontifícia Universidade Católica Do Rio Grande Do Sul (PUCRS). Dissertação (Mestrado em Educação) - Pontifícia Universidade Católica do Rio Grande do Sul, Porto Alegre, 2015.

TRISTÃO, M.. Saberes e fazeres da educação ambiental no cotidiano escolar. Revista Brasileira de Educação Ambiental, Brasília, n.0, p.47-55, 2004. 